\title{
PENGENDALIAN FAKTOR RISIKO STUNTING ANAK BADUTA DI SULAWESI TENGAH
}

\author{
The Control Risk Factor Stunting Children Under \\ Two Years in Central of Sulawesi
}

\author{
Nasrul \\ Poltekkes Kemenkes Palu \\ Email: sahenasrul@gmail.com
}

\begin{abstract}
ABSTRAK
Stunting merupakan perhatian utama kesehatan masyarakat di seluruh dunia. Tujuan penelitian menganalisis faktor risiko baduta stunting di Sulawesi Tengah dan model pengendaliannya. Penelitian Cross Sectional dilaksanakan pada tanggal 06 Juli-31 Agusutus 2018 di Kota Palu, Kabupaten Poso, Sigi dan Kabupaten Banggai di Provinsi Sulawesi Tengah. Populasi semua anak baduta di Sulawesi Tengah. Metode penarikan sampel dengan simple random sampling sebanyak 384 orang. Stunting adalah status gizi anak 0-23 bulan skor TB/U < -2SD Standar WHO 2005. Data diperoleh dengan wawancara menggunakan kuesioner, Faktor risiko yang paling dominan dilakukan analisis multivariat regresi logistik terhadap variabel faktor risiko risiko rumah tangga dan keluarga, risiko makanan pendamping ASI, risiko praktek menyusui, risiko penyakit infeksi, risiko sosial dan masyarakat. Analisis bivariat nilai $\mathrm{p}$ $<0,25$ dilanjutkan dengan uji regresi logistik. Selanjutnya faktor risiko dominan dikendalikan dengan model promosi multilevel dengan pendekatan Multilevel Approach To Community Health (MATCH). Hasil penelitian menunjukkan variabel yang memiliki faktor risiko terhadap kejadian stunting adalah berat badan lahir rendah OR=5,512 $(1,992-15,256)$ tidak mencuci tangan OR=5,359 $(1,758-16,341)$ serta tidak memiliki jamban dengan $\mathrm{OR}=7,398(2,072-30,714)$. Model MATCH dengan melaksanakan program peningkatan efektivitas program Kesehatan ibu dan anak seperti antenatal care, kelas ibu hamil, suplementasi Fe dan kalsium. Pemberian makanan tambahan ibu hamil. Pelatihan praktik mencuci tangan pada air mengalir menggunakan sabun. Dukungan prasarana Air bersih dengan pemipaan. Bantuan kepemilikan jamban dan cara perawatannya serta pelatihan sanitasi berbasis masyarakat.
\end{abstract}

Kata Kunci : Pengendalian, stunting, match model

\section{ABSTRACT}

Stunting is a major concern for public health throughout the world. The purpose of the study was to analyze the negative stunting factors in Central Sulawesi and the control model. Cross Sectional Research was conducted on July 6-August 31, 2018 in Palu City, Poso District, Sigi and Banggai District in Central Sulawesi Province. The population of all baduta children in Central Sulawesi. The sampling method with simple random sampling was 384 people. Stunting is WHO nutritional status of 0-23 months TB / U score <2SD. WHO Standard 2005. Data used by interviews using questionnaires, The most dominant factor performs multivariate logistic regression on risk factors for household and family ASI, calculates practice, measure infection, and social society. Bivariate analysis Value of $p<0.25$ Continue with logistic regression test. In addition, the factors that are relevant to multilevel promotion models are the Multilevel Approach To Community Health (MATCH) approach. The results showed the variables that had factors on the incidence of stunting were low birth weight $O R=5.512(1,992-15,256)$ not washing hands $O R=5,359(1,758$ 16,341) and not having a toilet with $O R=7,398(2,072-30,714)$ The MATCH model by implementing programs to improve maternal and child health programs such as antenatal care, classes for pregnant women, Fe and calcium supplementation. Providing food for pregnant women. Training in the practice of washing hands with running water using soap. Infrastructure support Clean water with piping. Latrine ownership assistance and how to treat it also community-based sanitation training.

Keywords : Control, stunting, match model

\section{Sekretariat}

Editorial: Kampus FKM UNISMUH PALU - Palu 94118, Sulawesi Tengah, Indonesia

Telp/HP: +6281245936241, Fax (0451) 425627

E-mail: jurnal.mppki@gmail.com

OJS: http://jurnal.unismuhpalu.ac.id/index.php/PJKM

Article History:
$\Rightarrow \quad$ Received 08 September 2018
$\Rightarrow \quad$ Revised 06 Oktober 2018
$\Rightarrow \quad$ Accepted 22 November 2018
$\Rightarrow \quad$ Available online 31 Desember 2018




\section{PENDAHULUAN}

Stunting merupakan perhatian utama kesehatan masyarakat di seluruh dunia (Bata et al., 2017). Prevalensi stunting didefinisikan sebagai proporsi anak-anak yang memiliki tinggi badan menurut umur <-2SD standar pertumbuhan anak WHO (Onis, Blo, \& Borghi, 2011) Stunting pada anak-anak adalah hasil dari beberapa keadaan dan faktor penentu termasuk prahamil, intrauterus dan kekurangan gizi setelah lahir (Adair et al., 2013) Stunting pada kehidupan awal dikaitkan dengan konsekuensi fungsional yang merugikan, rendahnya kognisi dan kinerja pendidikan, pendapatan yang rendah pada saat dewasa, hilangnya produktivitas, meningkatnya risiko penyakit kronis yang berhubungan dengan masalah gizi (Black et al., 2013) Intervensi dini dapat mencegah hasil tersebut dan juga menurunkan resiko kematian ibu (de Onis, Blössner, \& Borghi, 2012).

Penelitian di Indonesia menunjukkan stunting berkaitan dengan berat badan lahir rendah, sedang disusui selama 6 bulan atau lebih, memiliki orang tua yang pendek, dan ibu-ibu yang tidak pernah mengikuti pendidikan formal. Stunting juga lebih tinggi di daerah pedesaan (Rachmi, CN; Agho KE; Li, 2016). Dalam skala lebih kecil penelitian pada anak usia 6-23 bulan menunjukkan bahwa tentang faktor risiko stunting adalah berat badan lahir rendah, usia anak 12-23 bulan, tinggi badan ibu $<150 \mathrm{~cm}$, pengasuh anak tidak mencuci tangan menggunakan sabun serta imunisasi dasar yang tidak lengkap (Nasrul, Hafid, Razak Thaha, \& Suriah, 2015).

Riset Kesehatan Dasar (Riskesdas) Kementerian Kesehatan Republik Indonesia melaporkan prevalensi stunting balita secara nasional tahun 2013 adalah 37,2\%, yang berarti terjadi peningkatan dibandingkan tahun 2010 (35,6\%) dan 2007 (36,8\%). Total stunting balita di Sulawesi Tengah tahun 2013 sebesar 41\% dan di Kota Palu sebesar 21,42\% (Nasrul, 2015).

Prevalensi stunting pada baduta di Sulawesi Tengah pada tahun 2007, 2011 dan 2016 berturut-turut 32,3\%, 31,5\% dan 26,0\%. Dalam 9 tahun terakhir terjadi penurunan $6,2 \%$ atau rata-rata $0,6 \%$ pertahun (Hafid, Maudu, \& Nasrul, 2017). Meskipun terjadi penurunan, namun masalah stunting masih perlu dikendalikan. Peningkatan komitmen untuk mengevaluasi pengobatan dan intervensi pencegahan di tingkat kesehatan masyarakat, penanganan dari waktu intervensi, dan sejauh mana pencegahan stunting dapat dicapai, diperlukan untuk menginformasikan ke pihak lain upaya untuk mengatasi stunting dan konsekuensinya (Angood, Khara, Dolan, Berkley, \& Group, 2016).

Faktor langsung yang berkontribusi terhadap stunting yaitu: faktor rumah tangga dan keluarga, makanan pendamping ASI yang tidak memadai, praktek menyusui yang tidak memadai, faktor penyakit infeksi dan faktor tidak langsung adalah faktor sosial dan masyarakat (Stewart, Iannotti, Dewey, Michaelsen, \& Onyango, 2013). Berdasarkan permasalahan tersebut dan masih tingginya prevalensi stunting pada anak di bawah dua tahun di Sulawesi Tengah, perlu diteliti lebih lanjut faktor risiko apa saja yang menyebabkan stunting dan bagaimana model pengendaliannya.

Tujuan penelitian ini adalah menganalisis faktor risiko rumah tangga dan keluarga, makanan pendamping ASI, praktek menyusui, faktor penyakit infeksi dan faktor sosial dan masyarakat di Sulawesi Tengah dan model pengendalian faktor-faktor tersebut.

\section{BAHAN DAN METODE}

Penelitian observasional dengan desain Cross Sectional. Penelitian dilaksanakan pada tanggal 06 Juli - 31 Agusutus 2018 di Kota Palu, Kabupaten Poso, Sigi dan Kabupaten Banggai Provinsi Sulawesi Tengah. Populasi dalam penelitian ini semua anak baduta di Sulawesi Tengah. Metode penarikan sampel dengan Simple random sampling. Sampel sebanyak 384 orang. Data diperoleh dengan wawancara menggunakan kuesioner, Faktor anak meliputi riwayat berat dan panjang badan lahir, pemberian ASI dan Makanan Pendamping ASI (MP ASI), penyakit infeksi, pelayanan kesehatan dan imunisasi, jenis kelamin, usia anak. Faktor ibu meliputi pengetahuan ibu dan pola asuh terhadap baduta. Variabel pengetahuan dan pola asuh dikategorikan menjadi dua yaitu baik dan kurang baik dengan pendekatan uji normalitas. Total skor pengetahuan tidak berdistribusi normal sehingga dikategorikan baik jika skor $\geq$ median dan kurang baik jika skor $<$ median.

Total skor pola asuh ibu berdistribusi normal sehingga dikategorikan menjadi baik jika skor $\geq$ mean dan kurang baik jika <mean. Faktor lingkungan keluarga meliputi tinggi badan orang tua, 
pendidikan orang tua, pekerjaan, pendapatan, jumlah anggota keluarga, ketersediaan pangan, dan sanitasi lingkungan. Variabel sanitasi lingkungan terdiri dari beberapa pertanyaan, kemudian dari total skor dilakukan uji normalitas untuk dikategorikan menjadi baik dan kurang baik. Kuesioner sebelum digunakan dilakukan uji coba kuesioner pada 30 ibu yang mempunyai baduta di Labuan Beru dengan karakteristik yang hampir sama dengan lokasi penelitian yaitu terdapat banyak baduta stunting. Pengukuran antropometri stunting diukur berdasarkan parameter panjang/ tinggi badan menurut usia dibandingkan dengan standar antropometri WHO 2005. Pengukuran panjang badan untuk usia kurang dari 24 bulan atau yang belum dapat berdiri diukur panjang badan dengan menggunakan length measuring board dalam posisi tidur. Pemberian ASI dan MP ASI diukur dari riwayat memberikan ASI dan MP ASI dari mulai lahir sampai saat dilaksanakan penelitian terdiri dari beberapa pertanyaan tentang ASI Eksklusif, usia pemberian, jenis dan tahapan makanan pendamping ASI (MP-ASI) kemudian dari total skor dilakukan uji normalitas untuk dikategorikan menjadi baik dan kurang baik. Penyakit infeksi adalah suatu kondisi pada saat baduta diukur mengalami gangguan karena terjadinya infeksi saluran pernapasan akut (ISPA), diare, atau campak selama penelitian dengan didasarkan pada diagnosis dokter. Pelayanan kesehatan dan imunisasi diukur dari kelengkapan imunisasi dasar yaitu jumlah jenis imunisasi yang pernah diterima balita sesuai umur dan kondisi kesehatan. Pengetahuan ibu diukur dari kemampuan ibu dalam menjawab dengan benar pertanyaan yang berkaitan dengan stunting termasuk penyebab dan akibatnya. Pola pengasuhan berdasarkan perilaku ibu dalam kebiasaan mengasuh dan merawat balitanya, cara pemberian makan dan perawatan kesehatan. Ketersediaan pangan adalah kemampuan responden menjawab pertanyaan mengenai ketersediaan pangan di tingkat rumah tangga. Sanitasi lingkungan berdasarkan penggunaan sarana pembuangan limbah dan air minum yang sesuai standar kesehatan. Instrumen Penelitian; Komputer dengan Software WHO Antro 2005, Komputer dengan Software SPSS 17.00 dan Kuesioner.

Analisis data meliputi analisis univariat, bivariat dan multivariat. Analisis univariat dengan melakukan uji distribusi frekuensi. Analisis bivariat digunakan untuk mengetahui sejauh mana hubungan antara faktor-faktor yang diduga berhubungan dengan stunting dilakukan dengan uji kai kuadrat dengan tingkat kemaknaan (nilai $p=0,05$ ) dan interval (CI) 95\%. Untuk melihat faktor risiko yang paling dominan dilakukan analisis multivariat regresi logistik ganda terhadap variabel hasil analisis bivariat yang memiliki nilai $\mathrm{p}<0,25$ atau secara subtansi dianggap penting berhubungan terhadap stunting sehingga didapatkan model akhir dengan nilai $\mathrm{p} \leq 0,05$.

Penentuan model pengendalian faktor risiko didasarkan hasil analisis regresi logistik dikaitkan dengan kerangka pikir Stewart (Stewart CP, Lannotti L, Dewey KG, 2013) tentang penyebab stunting anak. Kerangka ini digunakan karena dalam menyusun perencanaan model pengendalian atau intervensi perlu mempertimbangkan faktor determinan. Model pengendalian faktor risiko dalam penelitian ini adalah promosi multilevel dengan pendekatan Multilevel Approach To Community Health (MATCH) (Fertman \& Allensworth, 2010). Pendekatan MATCH ini memfokuskan pada implementasi dengan perspektif sosioekologi dan mengembangkan intervensi multipel untuk mengatasi perilaku individu dan kondisi lingkungan dengan modifikasi faktor risiko utama, yaitu faktor anak, perilaku ibu dan kepemilikan jamban terhadap kejadian stunting baduta.

\section{HASIL}

Sampel Baduta yang memiliki riwayat berat lahir rendah sebanyak 15,6\%, berada pada kelompok usia $12-23$ bulan $(53,9 \%)$ berjenis kelamin perempuan $(52,3 \%)$. Ibu baduta yang memiliki tinggi badan $<150 \mathrm{~cm}$ sebanyak $29,2 \%$. Melahirkan pada usia $\geq 20$ 35 tahun sebanyak 81,5\%. Jarak kelahiran yang kurang dari 3 tahun sebanyak 18,5\%. Ibu yang melahirkan lebih dari 3 anak sebanyak 59,1\%. Usia kehamilan pada umumnya lebih dari 37 minggu yaitu sebanyak $81,5 \%$. Ibu yang menamatkan pendidikan lebih dari 9 tahun sebanyak 85,7\%. Pada umumnya keluarga baduta terdiri dari $<6$ orang anggota Rumah Tangga

sampel baduta yang memperoleh makanan selain ASI pada umur kurang atau sama dengan 6 bulan sebanyak 55,2\%, dan baduta yang telah mengasup snack dan mie instant sebanyak 43,0\%. Tabel 4.3 menunjukkan bahwa Ibu baduta yang melakukan inisiasi menyusu dini sebanyak 53,4\% memberikan kolostrum 60,7\% dan memberikan makanan pralakteal sebanyak 37,0\%. Sementara Tabel 4.4 Karakteristik risiko penyakit infeksi baduta dapat tergamabr dari perilaku Ibu anak baduta yang selalu mencuci tangan ketika menyiapkan makanan, menyusui atau selepas BAB sebayak $69,8 \%$ dengan riwayat diare badu- 
ta sebanyak 18,5\%. Informasi tentang imunisasi dasar anak baduta yang sudah lengkap sebanyak $81,0 \%$.

Sampel baduta yang terpapar asap rokok dalam rumah tangga sebanyak 22,9\%, tidak rutin ke posyandu 3,9\%, tidak memiliki jamban 17,2\% dan sumber air yang tidak terlindung sebanyak 13,0\%. Empat kabupaten kota yang terpilih menunjukkan prevalensi stunting baduta berkisar 18,8\%$24,0 \%$ tertinggi pada kota Palu dengan ratarata $21,6 \%$.

Faktor risiko rumah tangga dan keluarga yang signifikan terhadap kejadian baduta stunting di Sulawesi Tengah adalah berat badan lahir rendah $(p=0,000) \mathrm{Ke}-$ lompok Usia $(p=0,000)$ umur ibu $(p=0,000)$ jarak kelahiran $(\mathrm{p}=0,000)$ dan usia kehamilan $(\mathrm{p}=0,000)$ dan pendidikan ibu. Tidak ada faktor risiko makanan pendamping ASI baduta yang signifikan terhadap baduta stunting di Sulawesi Tengah. Tabel 4.9 juga menunjukkan tidak ada faktor risiko praktek menyusui yang signifikan terhadap baduta stunting di Sulawesi Tengah. Tabel 4.10 menunjukkan bahwa semua faktor risiko penyakit infeksi signifikan terhadap baduta stunting di Sulawesi Tengah seperti mencuci tangan $(p=0,000)$ riwayat penyakit diare $(p=0,000)$ dan kelengkapan imunisasi dasar $(p=0,000)$. semua faktor risiko risiko sosial dan masyarakat yang signifikan terhadap baduta stunting di Sulawesi Tengah seperti keterpaparan rokok $(p=0,000)$ kepemilikan jamban $(\mathrm{p}=0,000)$ dan sumber air yang tidak terlindung $(\mathrm{p}=0,000)$.

Analisis multivariat yang digunakan adalah regresi logistik dengan tujuan untuk Analisis multivariat yang digunakan adalah regresi logistik dengan tujuan untuk melihat pengaruh masing-masing variabel independen dengan variabel dependen secara bersamaan. Analisis multivariat yang dilakukan bertujuan untuk menentukan variabel yang paling dominan sebagai faktor risiko stunting. Setelah dilakukan uji bivariat, variabel yang memiliki nilai $p$ value $\leq 0,25$ adalah variabel berat lahir, kelompok usia, kategori umur ibu, pendidikan ibu, pemberian MP-ASI dini, mencuci tangan, imunisasi, keterpaparan rokok, kepemilikan jamban dan sumber air.

Hasil uji regresi logistik metode Backward pada step ke 4 menunjukkan variabel yang memiliki faktor risiko terhadap kejadian stunting setelah disesuaikan dengan variabel lain (Adjusted OR (95\% CI) berturut turut adalah berat badan lahir rendah $\mathrm{OR}=5,512$ $(1,992-15,256)$ tidak mencuci tangan OR=5,359 (1,758-16,341) serta tidak memiliki jamban dengan $\mathrm{OR}=7,398(2,072-30,714)$.

\section{PEMBAHASAN}

Penelitian ini menganalisis 384 sampel baduta dengan prevalensi stunting sebesar 21,6\%. Dilaksanakan pada tanggal 06 Juli - 31 Agusutus 2018 di Kota Palu, Kabupaten Poso, Sigi dan Kabupaten Banggai Provinsi Sulawesi Tengah. Pemilihan faktor risiko berdasarkan skema Stewart 2013 yang meliputi risiko rumah tangga dan keluarga dimana Sampel Baduta yang memiliki riwayat berat lahir rendah cukup tinggi yaitu 15,6\%, lebih dari setengah sampel berada pada kelompok usia 12-23 bulan, lebih banyak yang berjenis kelamin perempuan. Masih ada Ibu baduta yang memiliki tinggi badan $<150 \mathrm{~cm}$. Masih ada Jarak kelahiran yang kurang dari 3 tahun. Lebih dari setengah Ibu yang melahirkan lebih dari 3 anak. pada umumnya umur kehamilan ibu cukup 37 minggu. Ibu yang menamatkan pendidikan lebih dari 9 tahun cukup tinggi yaitu $85,7 \%$. Serta pada umumnya keluarga baduta terdiri dari $<6$ orang anggota Rumah Tangga.

Faktor risiko makanan pendamping ASI baduta menunjukkan bahwa lebih dari setengah sampel baduta yang memperoleh makanan selain ASI pada umur $\leq 6$ bulan, terdapat $43,0 \%$ baduta yang telah mengasup snack dan mie instant. Praktek inisiasi menyusu dini sudah cukup baik dimana lebih dari setengah Ibu baduta telah melakukannya. Pemberian kolostrum sudah cukup baik namun masih ada yang memberikan makanan pralakteal sebesar 37,0\%. Karakteristik risiko penyakit infeksi baduta dapat tergambar dari perilaku Ibu anak baduta yang selalu mencuci tangan ketika menyiapkan makanan, menyusui atau selepas Buang Air Besar (BAB) sebayak $69,8 \%$ dengan riwayat diare baduta sebanyak $18,5 \%$. Informasi tentang imunisasi dasar anak baduta yang sudah lengkap sebanyak $81,0 \%$. Sampel baduta yang terpapar asap rokok dalam rumah tangga sebanyak $22,9 \%$, tidak rutin ke posyandu 3,9\%, tidak memiliki jamban 17,2\% serta sumber air yang tidak terlindung sebanyak 13,0\%.

Faktor risiko rumah tangga dan keluarga 
yang signifikan terhadap kejadian baduta stunting di Sulawesi Tengah adalah berat badan lahir rendah $(p=0,000)$ Kelompok Usia $(\mathrm{p}=0,000)$ umur ibu $(\mathrm{p}=0,000)$ jarak kelahiran $(p=0,000)$ dan usia kehamilan $(p=0,000)$ dan pendidikan ibu. Hasil analisis ini menginformasikan bahwa bila membandingkan dengan kerangka stewart 2013 hampir semua faktor risiko rumah tangga dan keluarga terhadap stunting memiliki hubungan yang signifikan.

Hasil penelitian ini sejalan pula dengan beberapa penelitian sebelumnya yang menemukan bahwa terdapat hubungan yang signifikan antara riwayat status BBLR dengan status stunting pada baduta. Penelitian di Kabupaten Hulu Sungai Utara Kalimantan menunjukkan bahwa terdapat hubungan yang signifikan antara riwayat status BBLR (nilai $p=0,015$ ) dengan stunting pada anak baduta. BBLR merupakan faktor risiko yang paling dominan berhubungan dengan kejadian stunting. Anak dengan BBLR memiliki risiko 5,87 kali untuk mengalami stunting (Rahayu, Yulidasari, Putri, \& Rahman, 2015). Demikian pula hasil penelitian Mugni et al, (Muqni, Hadju, \& Jafar, 2012) menunjukkan bahwa berat lahir merupakan prediktor yang signifikan dalam menentukan status pendek pada bayi usia 12 -60 bulan di Makassar.

Berat lahir pada umumnya sangat terkait dengan kematian janin, neonatal dan pascaneonatal, morbiditas bayi dan anak serta pertumbuhan dan perkembangan jangka panjang. Dampak dari bayi yang memiliki berat lahir rendah akan berlangsung dari generasi ke generasi, anak dengan BBLR akan memiliki ukuran antropometri yang kurang pada perkembangannya. Dalam analisis multivariat tunggal variabel berat lahir rendah memiliki dampak yang besar terhadap stunting.

Hasil penelitian ini menunjukkan bahwa tidak ada faktor risiko makanan pendamping ASI baduta yang signifikan terhadap baduta stunting di Sulawesi Tengah. Demikian pula bahwa tidak ada faktor risiko praktek menyusui yang signifikan terhadap baduta stunting di Sulawesi Tengah. Sedangkan dari segi faktor risiko penyakit infeksi, semua faktor berhubungan secara signifikan terhadap baduta stunting di Sulawesi Tengah seperti mencuci tangan $(p=0,000)$ riwayat penyakit diare $(\mathrm{p}=0,000)$ dan kelengkapan imunisasi dasar $(p=0,000)$. Hasil analisis penelitian menunjukkan bahwa semua faktor risiko risiko sosial dan masyarakat yang signifikan terhadap baduta stunting di Sulawesi Tengah seperti keterpaparan rokok $(\mathrm{p}=0,000)$ kepemilikan jamban $(\mathrm{p}=0,000)$ dan sumber air yang tidak terlindung $(\mathrm{p}=0,000)$.

Pada negara berkembang, penyakit infeksi memang masih merupakan masalah utama, hasil penelitian ini menunjukkan bahwa faktor infeksi berpengaruh terhadap kejadian stunting. Perilaku mencuci tangan sebagai tindak pencegahan kontaminasi dalam penelitian ternyata merupakan determinan stunting baduta. Hasil penelitian Humphrey melaporkan bahwa penyakit lingkungan subklinis enteropati telah meningkatkan permeabilitas usus kecil untuk menjadi patogen sekaligus mengurangi penyerapan zat gizi. Hal inilah yang menyebabkan malnutrisi, stunting, bahkan dengan tanpa harus menderita diare (Humphrey, 2009).

Belajar dari program sanitasi pemerintah India, dimana program tersebut berpengaruh terhadap pengurangan kematian bayi dan juga meningkatkan rerata tinggi badan anak-anak di pedesaan India. Selama 3 tahun mulai tahun 1999 hingga tahun 2012, pemerintah India telah melaksanakan program sanitasi pedesaan yang dikenal dengan nama Total Sanitation Campaign. Di Maharashtra India, anak-anak yang tinggal di desa menerima perlakuan motivasi sanitasi dan subsidi pembangunan jamban. Hasilnya ternyata pertumbuhan tinggi badan anak-anak penerima motivasi dan subsidi jamban lebih tinggi daripada anak-anak di desa kontrol. Pelajaran yang dipetik dari program tersebut adalah bahwa dalam rangka mempersiapkan tujuan pembangunan berkelanjutan, disamping menyediakan akses terhadap air dan toilet, ada kebutuhan untuk meningkatkan kebersihan, terutama bagi perempuan dan anak perempuan. Sektor ini telah diamati selama bertahun-tahun bahwa air yang aman pada sumbernya sering tercemar oleh praktik penyimpanan air di tingkat rumah tangga, menyediakan toilet gratis tidak akan mengakibatkan penghentian buang air besar terbuka jika itu adalah pilihan sanitasi yang lebih disukai oleh anggota rumah tangga, dan 
mencuci tangan ternyata bukan perilaku yang sederhana untuk menjadi suatu kebiasaan (Hammer, 2013).

Bayi dan baduta yang berada pada fase belajar untuk makan sendiri, mengeksplorasi lingkungan dengan cara merangkak, memasukkan benda-benda di mulut merupakan aktifitas yang berisiko untuk mengalami kontaminasi makanan. Pembuangan tinja, pembuangan kotoran hewan dan kebersihan tangan menjadi hal penting selama periode usia sensitif ini. Akses yang cukup untuk air bersih dapat berfungsi sebagai penghalang penting untuk praktik kebersihan yang tepat dan persiapan yang aman dari makanan pendamping anak baduta. Literatur medis dan epidemiologi telah mendokumentasikan mekanisme yang menghubungkan antara buang air besar sembarangan dengan hambatan pertumbuhan pada awal kehidupan manusia (Hammer, 2013). Penelitian Fink et al. melaporkan bahwa kejadian stunting lebih rendah pada rumah tangga yang memiliki akses terhadap fasilitas sanitasi (Fink, Isabel, \& Hill, 2011). Selain itu, berbagai penelitian dari masing-masing negara baik analisis survei cross-sectional, penelitian longitudinal dan penelitian operasional menunjukkan bahwa peranan sanitasi sangat penting bagi pertumbuhan tinggi anak.

Sementara itu, Esrey melaporkan bahwa sumber air yang baik dapat menurunkan prevalensi stunting. Secara khusus, efek dari ketersedian air terhadap tinggi badan anak relatif kecil dan hanya berefek positif terhadap anak-anak pedesaan ketika pelayanan air yang tersedia ditingkatkan (Esrey, Potash, Roberts, \& Shiff, 1991). Rah et al menemukan bahwa efek perlindungan dari ibu atau pengasuh yang melaporkan praktik kebersihan pribadi terhadap stunting di India meningkat ketika mereka disertai dengan akses rumah tangga terhadap air melalui pemipaan. Sebuah meta-analisis data dari 14 uji coba cluster secara acak yang dilakukan di 10 negara berpenghasilan rendah dan menengah menemukan manfaat kecil intervensi air, sanitasi dan hygene pada tinggi anak di bawah usia lima tahun. Analisis dibatasi oleh kurangnya studi kualitas metodologis tinggi, terutama untuk sanitasi. Fasilitas Air Sanitasi dan Hygene yang rendah dan perilaku buruk dapat berdampak pada status gizi anak dengan menyebabkan diare, infeksi cacing usus atau penyakit enteropati. Infeksi dan kondisi ini secara langsung mempengaruhi status gizi melalui jalur hilangnya nafsu makan, kehilangan jaringan inang, pencernaan yang buruk atau malabsorpsi gizi, aktivasi kekebalan kronis dan tanggapan lain untuk infeksi yang mengalihkan penggunaan zat gizi dan energi, seperti demam (Rah et al., 2015).

Faktor risiko yang memengaruhi tinggi badan salah satu diantaranya adalah faktor kesehatan lingkungan seperti kepemilikan jamban. Penelitian di kabupaten banggai dan sigi menunjukkan bahwa rerata tinggi badan pada kelompok desa Stop Buang Air Besar Sembarangan (SBABS) lebih tinggi dibanding dengan kelompok desa non SBABS (Hafid, Djabu, Udin, \& Nasrul, 2017). Mekanisme ini dapat merujuk melalui apa yang disebut sebagai pencegahan tropical enteropathy, pencegahan diare dan penyakit infeksi lainnya yang menghambat penyerapan zatzat gizi pada pencernaan anak baduta. Penelitian Torlesse et al (2016) menunjukkan bahwa terdapat interaksi yang signifikan antara fasilitas sanitasi rumah tangga, pengolahan air rumah tangga dengan stunting. Prevalensi stunting secara signifikan lebih tinggi di antara anak-anak yang tinggal di rumah tangga tanpa memiliki jamban dibandingkan yang memiliki jamban (35,3\% vs 24,0\%); rumah tangga yang tidak menggunakan sabun untuk mencuci tangan dibandingkan dengan mereka yang melakukannya (31,6\% vs $25,8 \%$ ); dan rumah tangga yang minum air yang tidak diolah dibandingkan dengan yang diolah $(38,2 \%$ vs 27,3\%)(Torlesse, Cronin, Sebayang, \& Nandy, 2016). Claire menawarkan upaya peningkatan status gizi dengan cara mengurangi penyakit diare dan infeksi enteric oleh karena kontaminasi tinja manusia (Chase \& Ngure, 2016).

Setelah dilakukan analisis regresi logistik, faktor risiko stunting pada baduta di Sulawesi Tengah adalah berat lahir rendah, perilaku tidak mencuci tangan dan tidak memiliki jamban. Berdasarkan skema Multilevel Approach to Community Health (MATCH) maka dapat dilakukan model pengendalian faktor risiko stunting pada baduta dengan cara:

Fase pertama adalah menyeleksi tujuan dalam hal ini tujuan utamnya adalah 
melakukan pencegahan stunting pada baduta. Indikator status kesehatan yang dipilih dan diprioritaskan adalah stunting. Sejalan dengan Isu Kementerian Kesehatan pada tahun 2018 ini, stunting merupakan isu masalah kesehatan utama, perubahan yang mampu dilakukan adalah meningkatkan kesehatan ibu hamil terkait dengan bayi berat lahir rendah termasuk didalamnya pemberian tablet $\mathrm{Fe}$, tablet kalsium dan asupan gizi ibu hamil. Perilaku tidak mencuci tangan terkait dengan dengan ketersediaan air, fasilitas air mengalir kesadaran dan ketersediaan sumber daya, dan sasaran status kesehatan ditulis, Populasi yang paling berisiko diidentifikasi. Perilaku yang relevan untuk memodifikasi sasaran status kesehatan dipilih, dan tujuan perilaku ditulis dan Faktor lingkungan yang berkaitan dengan sasaran status kesehatan dan tujuan perilaku diidentifikasi, dan tujuan lingkungan tertulis.

Fase Kedua adalah rencana intervensi dengan langkah Target intervensi utama diidentifikasi (yaitu individu yang memiliki tingkat kontrol atas perilaku atau faktor lingkungan yang terkait dengan tujuan status kesehatan). Tujuan intervensi. Kerangka intervensi, termasuk variabel teoritis dan variabel perantara lainnya, dibuat. Pendekatan intervensi misalnya, media advokasi, komunikasi kesehatan, atau sesi pendidikan diidentifikasi. Fase ketiga adalah pengembangan program yang meliputi langkah Komponen program utama diidentifikasi. Kurikulum diperoleh atau dibuat. Rencana pelajaran dikembangkan. Materi, persediaan, dan sumber daya lainnya dikumpulkan.

Fase Keempat adalah persiapan implementasi yang meliputi langkah Struktur pendukung termasuk advokasi di masyarakat, dukungan dari pemangku kepentingan utama, dan mempromosikan program kepada populasi dikembangkan. Personil yang akan melaksanakan program dilatih. Fase kelima adalah evaluasi yang meliputi tahap proses kelayakan, penerimaan, dampak terhadap hasil belajar dilakukan. Evaluasi dampak termasuk perubahan lingkungan, perilaku, variabel teoritis, dan variabel kognitif seperti pengetahuan dan sikap dilakukan. Dalam evaluasi hasil, perubahan status kesehatan dinilai.

\section{KESIMPULAN DAN SARAN}

Faktor risiko stunting pada baduta di Sulawesi Tengah adalah berat lahir rendah, perilaku tidak mencuci tangan dan tidak memiliki jamban. Model Multilevel Approach to Community Health (MATCH) merupakan pilihan penanggulangan stunting di Sulawesi Tengah dengan melaksanakan program peningkatan efektivitas program Kesehatan ibu dan anak seperti antenatal care, kelas ibu hamil, suplementasi Fe dan kalsium. Pemberian makanan tambahan ibu hamil. Pelatihan praktik mencuci tangan pada air mengalir menggunakan sabun. Dukungan prasarana Air bersih dengan pemipaan. Bantuan kepemilikan jamban dan cara perawatannya serta pelatihan sanitasi berbasis masyarakat. Disarankan agar program peningkatan efektivitas program Kesehatan ibu dan anak seperti Antenatal care, Kelas Ibu Hamil, Suplementasi Fe dan Kalsium. Pemberian makanan tambahan ibu hamil. Pelatihan Praktik Mencuci tangan pada air mengalir menggunakan sabun. Dukungan prasarana Air bersih dengan pemipaan. Bantuan Kepemilikan Jamban dan cara perawatannya serta pelatihan sanitasi berbasis masyarakat.

\section{UCAPAN TERIMA KASIH}

Terima kasih dapat diberikan kepada 1) Kepala Badan PPSDM Kesehatan , 2) Kepala Dinas Kesehatan Kabupaten Banggai, Poso, Sigi dan Kota Palu dan 3) Fahmi Hafid 4) terkhusus kepada Responden dan Enumerator penelitian ini.

\section{DAFTAR PUSTAKA}

Adair, L. S., Fall, C. H. D., Osmond, C., Stein, A. D., Martorell, R., Ramirez-Zea, M., ... Victora, C. G. (2013). Associations of linear growth and relative weight gain during early life with adult health and human capital in countries of low and middle income: Findings from five birth cohort studies. The Lancet, 382(9891), 525-534. https://doi.org/10.1016/ S0140-6736(13)60103-8

Angood, C., Khara, T., Dolan, C., Berkley, J. A., \& Group, W. T. I. (2016). Research Priorities on the Relationship between Wasting and Stunting. Plos One, 11(5), e0153221. https://doi.org/10.1371/ journal.pone.0153221 
Bata, P., Binh, L., Vonaesch, P., Tondeur, L., Nguyen, L., Frank, T., ... Vray, M. (2017). Factors associated with stunting in healthy children aged 5 years and less living in Bangui ( RCA ). PLoS ONE, 12(8), 1-17. https:// doi.org/10.1371/journal.pone.0182363

Black, R. E., Victora, C. G., Walker, S. P., Bhutta, Z. A., Christian, P., De Onis, M., ... Uauy, R. (2013). Maternal and child undernutrition and overweight in lowincome and middle-income countries. The Lancet, 382(9890), 427-451. https://doi.org/10.1016/S0140-6736 (13)60937-X

Chase, C., \& Ngure, F. (2016). Multisectoral Approaches to Improving Nutrition: Water , Sanitation, and Hygiene, (February).

de Onis, M., Blössner, M., \& Borghi, E. (2012). Prevalence and trends of stunting among pre-school children, 19902020. Public Health Nutrition, 15(01), 142-148. https://doi.org/10.1017/ S1368980011001315

Esrey, S. A., Potash, J. B., Roberts, L., \& Shiff, C. (1991). Reviews / Analyses Effects of improved water supply and sanitation on, (Table 1).

Fertman, C. I., \& Allensworth, D. D. (2010). Health promotion programs: from theory to practice. (C. I. Fertman \& D. D. Allensworth, Eds.) (First Edit). San Francisco: Jossey-Bass A Wiley Imprint.

Fink, G., Isabel, G., \& Hill, K. (2011). The effect of water and sanitation on child health: Evidence from the demographic and health surveys 1986-2007. International Journal of Epidemiology, 40(5), 1196 -1204. https://doi.org/10.1093/ije/ dyr102

Hafid, F., Djabu, U., Udin, \& Nasrul. (2017). Efek Program SBABS Terhadap Pencegahan Stunting Anak Baduta di Kabupaten Banggai dan Sigi. Indonesian Journal of Human Nutrition, 4(2), 79-87. Retrieved from ijhn.ub.ac.id/ index.php/ijhn/article/view/223

Hafid, F., Maudu, R., \& Nasrul, N. (2017). Trend dan prevalensi stunting baduta tahun 2007 -2016 di sulawesi tengah. Preventif, 8(2).

Hammer, J. (2013). Village Sanitation and Children's Human Capital Evidence from a Randomized Experiment by the Maharashtra Government. Washington, DC.

Humphrey, J. H. (2009). Child undernutrition, tropical enteropathy, toilets, and handwashing. The Lancet, 374(9694), 10321035. https://doi.org/10.1016/S01406736(09)60950-8

Muqni, A. D., Hadju, V., \& Jafar, N. (2012). Hubungan Berat Badan Lahir Dan Pelayanan KIA Terhadap Status Gizi Anak Balita Di Kelurahan Tamamaung Makassar. Media Gizi Masyarakat Indonesia, 1, 109-116.

Nasrul, Hafid, F., Razak Thaha, A., \& Suriah. (2015). Faktor Risiko Stunting Usia 623 Bulan dI Kecamatan Bontoramba Kabupaten Jeneponto. Media Kesehatan Masyarakat Indonesia, 11(3), 139-146. https://doi.org/http:// dx.doi.org/10.30597/mkmi.v11i3

Nasrul, N. (2015). Determinan Stunting Pada Anak Usia 6-23 Bulan di Kota Palu Sulawesi Tengah. Palu.

Onis, M. De, Blo, M., \& Borghi, E. (2011). Prevalence and trends of stunting among pre-school children , 1990 2020. Public Health Nutrition, 15(1), 142-148. https://doi.org/10.1017/ S1368980011001315

Rachmi, CN; Agho KE; Li, M. B. LA. (2016). Stunting, Underweight and Overweight in Children Aged 2.0-4.9 Years in Indonesia: Prevalence Trends and Associated Risk Factors. Plosone, 11(5), 1-18. https://doi.org/10.1371/ journal.pone.0154756

Rah, J. H., Cronin, A. A., Badgaiyan, B., Aguayo, V. M., Coates, S., \& Ahmed, S. (2015). Household sanitation and personal hygiene practices are associated with child stunting in rural India: a crosssectional analysis of surveys. BMJ Open, 5(2), e005180. https:// doi.org/10.1136/bmjopen-2014005180

Rahayu, A., Yulidasari, F., Putri, A. O., \& Rahman, F. (2015). Riwayat Berat Badan Lahir dengan Kejadian Stunting pada Anak Usia Bawah Dua Tahun. Kesmas: National Public Health Journal, 10(2), 67. https://doi.org/10.21109/ kesmas.v10i2.882 
Stewart, C. P., Iannotti, L., Dewey, K. G., Michaelsen, K. F., \& Onyango, A. W. (2013). Contextualising complementary feeding in a broader framework for stunting prevention. Maternal and Child Nutrition, 9(S2), 27-45. https:// doi.org/10.1111/mcn.12088

Stewart CP, Lannotti L, Dewey KG, M. K. \& O. A. (2013). Childhood Stunting: Context, Causes and Consequences WHO Conceptual framework. Maternal and Chind Nutrition, 9(September), 27-45.

Torlesse, H., Cronin, A. A., Sebayang, S. K., \& Nandy, R. (2016). Determinants of stunting in Indonesian children: evidence from a cross-sectional survey indicate a prominent role for the water, sanitation and hygiene sector in stunting reduction. BMC Public Health, 16(1), 669. https://doi.org/10.1186/ s12889-016-3339-8 


\section{LAMPIRAN}

Tabel 1. Karakteristik risiko rumah tangga dan keluarga baduta di Sulawesi Tengah tahun 2018

\begin{tabular}{|c|c|c|}
\hline Faktor rumah tangga dan keluarga & $\mathbf{n}$ & $\%$ \\
\hline \multicolumn{3}{|l|}{ Berat Badan Lahir } \\
\hline Rendah: $<2500 \mathrm{gr}$ & 60 & 15,6 \\
\hline Normal: $2500-4000 \mathrm{grl}$ & 324 & 84,4 \\
\hline \multicolumn{3}{|l|}{ Usia anak } \\
\hline $12-23$ bulan & 207 & 53,9 \\
\hline $6-11$ bulan & 177 & 46,1 \\
\hline \multicolumn{3}{|l|}{ Jenis kelamin anak } \\
\hline Laki-laki & 183 & 47,4 \\
\hline Perempuan & 201 & 52,3 \\
\hline \multicolumn{3}{|l|}{ Tinggi badan Ibu } \\
\hline$<150 \mathrm{~cm}$ & 115 & 29,2 \\
\hline$\geq 150 \mathrm{~cm}$ & 269 & 70,1 \\
\hline \multicolumn{3}{|l|}{ Usia ibu saat melahirkan } \\
\hline$<20$ dan $>35$ tahun & 71 & 18,5 \\
\hline$\geq 20-35$ Tahun & 313 & 81,5 \\
\hline \multicolumn{3}{|l|}{ Jarak kelahiran } \\
\hline$<3$ tahun & 71 & 18,5 \\
\hline$\geq 3$ tahun & 313 & 81,5 \\
\hline \multicolumn{3}{|l|}{ Paritas } \\
\hline$>3$ Anak & 227 & 59,1 \\
\hline$\leq 3$ anak & 157 & 40,9 \\
\hline \multicolumn{3}{|l|}{ Usia kehamilan } \\
\hline$<37$ Minggu & 71 & 18,5 \\
\hline$\geq 37$ minggu & 313 & 81,5 \\
\hline \multicolumn{3}{|l|}{ Lama pendidikan ibu } \\
\hline$<9$ tahun & 55 & 14,3 \\
\hline$\geq 9$ tahun & 329 & 85,7 \\
\hline \multicolumn{3}{|l|}{ Jumlah anggota rumah tangga } \\
\hline$\geq 6$ orang ART & 102 & 26,2 \\
\hline$<6$ orang ART & 282 & 73,4 \\
\hline
\end{tabular}

Sumber: Data Primer, 2018

Tabel 2. Karakteristik risiko makanan pendamping ASI baduta di Sulawesi Tengah tahun 2018

\begin{tabular}{ccc}
\hline Faktor risiko makanan pendamping ASI & n & $\mathbf{\%}$ \\
\hline Pemberian MP-ASI & 212 & 55,2 \\
Pemberian MP ASI <6 bulan & 172 & 44,8 \\
Pemberian MP ASI $\geq 6$ bulan & & \\
\hline Asupan snack dan mie instant & 165 & 43,0 \\
Mengasup & 219 & 57,0 \\
Tidak mengasup & \\
\hline
\end{tabular}

Sumber: Data Primer, 2018 


\section{Tabel 3. Karakteristik risiko praktek menyusui baduta di Sulawesi Tengah tahun 2018}

\begin{tabular}{lcc}
\hline Faktor risiko praktek menyusui & $\mathbf{n}$ & $\mathbf{\%}$ \\
\hline Inisiasi menyusui dini & & \\
Tidak menginisiasi menyusui dini & 179 & 46,6 \\
Menginisiasi menyusui dini & 205 & 53,4 \\
\hline Pemberian kolostrum & 151 & 39,3 \\
kolostrum dibuang & 233 & 60,7 \\
kolostrum diberikan & & \\
\hline Pemberian makanan pre-lakteal & 142 & 37,0 \\
Memberi makanan pralakteal & 242 & 63,0 \\
\hline Tidak Memberi makanan pralakteal & & \\
\hline
\end{tabular}

Sumber: Data Primer, 2018

\section{Tabel 4. Karakteristik risiko penyakit infeksi baduta di Sulawesi Tengah tahun 2018}

\begin{tabular}{lcc}
\hline Faktor risiko penyakit infeksi & n & $\mathbf{\%}$ \\
\hline Mencuci tangan & & 30,2 \\
Tidak atau kadang-kadang mencuci tangan & 116 & 69,8 \\
Selalu mencuci tangan & 268 & 18,5 \\
\hline Riwayat penyakit diare & 71 & 81,5 \\
Diare & 313 & 19,0 \\
Tidak diare & & 81,0 \\
\hline Kelengkapan imunisasi dasar anak & 73 & 311 \\
Imunisasi dasar tidak lengkap & & \\
Imunisasi dasar lengkap & & \\
\hline
\end{tabular}

Sumber: Data Primer, 2018

Tabel 5. Karakteristik risiko sosial dan masyarakat baduta di Sulawesi Tengah tahun 2018

\begin{tabular}{lcc}
\hline Faktor rumah tangga dan keluarga & $\mathbf{n}$ & $\mathbf{\%}$ \\
\hline Keterpaparan asap rokok & 88 & 22,9 \\
Ada ART yang merokok dalam rumah & 296 & 77,1 \\
Tidak ada ART yang merokok dalam rumah & & 3,9 \\
\hline Partisipasi ke posyandu & 15 & 96,1 \\
Tidak Rutin & 369 & 17,2 \\
Rutin & 66 & 82,8 \\
\hline Kepemilikan jamban & 318 & 13,0 \\
Tidak memiliki Jamban & & 87,0 \\
Memiliki Jamban & 50 & 22,9 \\
\hline Sumber air & 334 & 77,1 \\
Sumber air tidak terlindung. & 88 & 3,9 \\
Sumber air terlindungi. & 296 & 96,1 \\
\hline Keterpaparan asap rokok & & \\
Ada ART yang merokok dalam rumah & 15 & 369 \\
\hline Tidak ada ART yang merokok dalam rumah & & \\
\hline Tidak Rutin & & \\
Rutin & & \\
\hline
\end{tabular}

Sumber: Data Primer, 2018 
Tabel 6. Faktor risiko rumah tangga dan keluarga dengan baduta stunting di Sulawesi Tengah tahun 2018

\begin{tabular}{|c|c|c|c|c|c|c|}
\hline \multirow{3}{*}{ Variabel Independen } & \multicolumn{4}{|c|}{ Variabel Dependen } & \multirow{3}{*}{ Total } & \multirow{3}{*}{$\rho$-value } \\
\hline & \multicolumn{2}{|c|}{ Stunting } & \multicolumn{2}{|c|}{ Normal } & & \\
\hline & $\mathbf{n}$ & $\%$ & $\bar{n}$ & $\%$ & & \\
\hline \multicolumn{7}{|l|}{ Berat Badan Lahir (gr) } \\
\hline BBLR & 33 & 55,0 & 27 & 45,0 & 60 & $0,000^{*}$ \\
\hline Tidak BBLR & 50 & 15,4 & 274 & 84,6 & 324 & \\
\hline \multicolumn{7}{|l|}{ Kelompok Usia } \\
\hline $12-23$ bulan & 63 & 30,4 & 144 & 69,6 & 207 & $0,000^{*}$ \\
\hline 0-11 bulan & 20 & 11,3 & 157 & 88,7 & 177 & \\
\hline \multicolumn{7}{|l|}{ Jenis Kelamin } \\
\hline Laki-laki & 43 & 23,5 & 140 & 76,5 & 183 & 0,392 \\
\hline Perempuan & 40 & 19,9 & 161 & 80,1 & 201 & \\
\hline \multicolumn{7}{|l|}{ Tinggi Badan Ibu } \\
\hline$<150 \mathrm{~cm}$ & 28 & 24,3 & 87 & 75,7 & 115 & 0,395 \\
\hline$\geq 150 \mathrm{~cm}$ & 55 & 20,4 & 214 & 79,6 & 269 & \\
\hline \multicolumn{7}{|l|}{ Umur Ibu } \\
\hline$<20$ dan $>35$ Thn & 64 & 90,1 & 7 & 9,9 & 71 & $0,000 *$ \\
\hline 20 - 35 Tahun & 19 & 6,1 & 294 & 93,9 & 313 & \\
\hline \multicolumn{7}{|l|}{ Jarak Kelahiran } \\
\hline$<3$ tahun & 64 & 90,1 & 7 & 9,9 & 71 & $0,000^{*}$ \\
\hline$\geq 3$ Tahun & 19 & 6,1 & 294 & 93,9 & 313 & \\
\hline \multicolumn{7}{|l|}{ Paritas } \\
\hline$>3$ anak & 48 & 21,2 & 179 & 78,9 & 227 & 0,887 \\
\hline$\leq 3$ anak & 35 & 22,3 & 122 & 77,7 & 157 & \\
\hline \multicolumn{7}{|l|}{ Usia Kehamilan } \\
\hline <37 Minggu & 64 & 90,1 & 7 & 9,9 & 71 & $0,000^{*}$ \\
\hline$\geq 37$ Minggu & 19 & 6,1 & 294 & 93,9 & 313 & \\
\hline \multicolumn{7}{|l|}{ Lama pendidikan Ibu } \\
\hline$<9$ Tahun & 48 & 87,3 & 7 & 12,7 & 55 & $0,000^{*}$ \\
\hline$\geq 9$ Tahun & 35 & 10,6 & 294 & 89,4 & 329 & \\
\hline \multicolumn{7}{|l|}{ Jumlah ART } \\
\hline$\geq 6$ orang & 26 & 25,5 & 76 & 74,5 & 102 & 0,267 \\
\hline$<6$ orang & 57 & 20,2 & 225 & 79,8 & 282 & \\
\hline
\end{tabular}

Sumber: Data Primer, 2018 
Tabel 7. Faktor risiko makanan pendamping ASI baduta dengan baduta stunting di Sulawesi Tengah Tahun 2018

\begin{tabular}{|c|c|c|c|c|c|c|}
\hline \multirow{3}{*}{ Variabel Independen } & \multicolumn{4}{|c|}{ Variabel Dependen } & \multirow[t]{3}{*}{ Total } & \multirow[t]{3}{*}{$\rho$-value } \\
\hline & \multicolumn{2}{|c|}{ Stunting } & \multicolumn{2}{|c|}{ Normal } & & \\
\hline & $\bar{n}$ & $\%$ & $\bar{n}$ & $\%$ & & \\
\hline \multicolumn{7}{|l|}{ Pemberian MP-ASI } \\
\hline$<6$ bulan & 52 & 24,5 & 160 & 75,5 & 212 & 0,157 \\
\hline$\geq 6$ bulan & 31 & 18,0 & 141 & 82,0 & 172 & \\
\hline \multicolumn{7}{|l|}{ Asupan snack dan mie instant } \\
\hline Mengasup & 37 & 22,4 & 128 & 77,6 & 165 & 0,834 \\
\hline Tidak Mengasup & 46 & 21,0 & 173 & 79,0 & 219 & \\
\hline
\end{tabular}

Sumber: Data Primer, 2018

Tabel 8. Faktor risiko praktek menyusui dengan baduta stunting di Sulawesi Tengah Tahun 2018

\begin{tabular}{|c|c|c|c|c|c|c|}
\hline \multirow{3}{*}{ Variabel Independen } & \multicolumn{4}{|c|}{ Variabel Dependen } & \multirow[t]{3}{*}{ Total } & \multirow[t]{3}{*}{$\rho$-value } \\
\hline & \multicolumn{2}{|c|}{ Stunting } & \multicolumn{2}{|c|}{ Normal } & & \\
\hline & $\mathbf{n}$ & $\%$ & $\mathbf{n}$ & $\%$ & & \\
\hline \multicolumn{7}{|l|}{ Inisiasi menyusui dini } \\
\hline Tidak & 40 & 22,3 & 139 & 77,7 & 179 & \multirow[t]{2}{*}{0,840} \\
\hline Ya & 43 & 21,0 & 162 & 79,0 & 205 & \\
\hline \multicolumn{7}{|l|}{ Pemberian kolostrum } \\
\hline Dibuang & 34 & 22,5 & 117 & 77,5 & 151 & \multirow{2}{*}{0,827} \\
\hline Diberikan & 49 & 21,0 & 184 & 79,0 & 233 & \\
\hline \multicolumn{7}{|l|}{ Pemberian makanan pre-lakteal } \\
\hline Diberikan & 32 & 22,5 & 110 & 77,5 & 142 & \multirow{2}{*}{0,836} \\
\hline Tidak diberikan & 51 & 21,1 & 191 & 78,9 & 242 & \\
\hline
\end{tabular}

Sumber: Data Primer, 2018 
Tabel 9. Faktor Risiko penyakit infeksi dengan baduta stunting di Sulawesi Tengah Tahun 2018

\begin{tabular}{|c|c|c|c|c|c|c|}
\hline \multirow{3}{*}{ Variabel Independen } & \multicolumn{4}{|c|}{ Variabel Dependen } & \multirow{3}{*}{ Total } & \multirow{3}{*}{$\rho$-value } \\
\hline & \multicolumn{2}{|c|}{ Stunting } & \multicolumn{2}{|c|}{ Normal } & & \\
\hline & $\mathbf{n}$ & $\%$ & $\bar{n}$ & $\%$ & & \\
\hline \multicolumn{7}{|l|}{ Mencuci Tangan } \\
\hline $\begin{array}{l}\text { Tidak atau kadang-kadang } \\
\text { mencuci tangan }\end{array}$ & 70 & 60,3 & 46 & 39,7 & 116 & \multirow[t]{2}{*}{$0,000^{*}$} \\
\hline Selalu mencuci tangan & 13 & 4,9 & 255 & 95,1 & 268 & \\
\hline \multicolumn{7}{|l|}{ Riwayat penyakit diare } \\
\hline Diare & 64 & 90,1 & 7 & 9,9 & 71 & \multirow{2}{*}{$0,000^{*}$} \\
\hline Tidak Diare & 19 & 6,1 & 294 & 93,9 & & \\
\hline \multicolumn{7}{|l|}{$\begin{array}{l}\text { Kelengkapan imunisasi dasar anak } \\
\text { Tidak lengkap }\end{array}$} \\
\hline & 58 & 79,5 & 15 & 20,5 & 73 & \multirow[t]{2}{*}{$0,000^{*}$} \\
\hline Lengkap & 25 & 8,0 & 286 & 92,0 & 311 & \\
\hline
\end{tabular}

Sumber: Data Primer, 2018

Tabel 10. Faktor risiko sosial dan masyarakat dan stunting baduta di Sulawesi Tengah Tahun 2018

\begin{tabular}{|c|c|c|c|c|c|c|}
\hline \multirow{3}{*}{ Variabel Independen } & \multicolumn{4}{|c|}{ Variabel Dependen } & \multirow{3}{*}{ Total } & \multirow{3}{*}{$\rho$-value } \\
\hline & \multicolumn{2}{|c|}{ Stunting } & \multicolumn{2}{|c|}{ Normal } & & \\
\hline & $\mathbf{n}$ & $\%$ & $\bar{n}$ & $\%$ & & \\
\hline \multicolumn{7}{|l|}{ Keterpaparan asap rokok } \\
\hline Ya & 64 & 72,7 & 24 & 27,3 & 88 & \multirow{2}{*}{$0,000^{*}$} \\
\hline Tidak & 19 & 6,4 & 277 & 93,6 & 296 & \\
\hline \multicolumn{7}{|l|}{ Partisipasi ke posyandu } \\
\hline Tidak Rutin & 3 & 20,0 & 12 & 80,0 & 15 & \multirow[t]{2}{*}{1,000} \\
\hline Rutin & 80 & 21,7 & 289 & 78,3 & 369 & \\
\hline \multicolumn{7}{|l|}{ Kepemilikan jamban } \\
\hline Tidak Memiliki & 57 & 86,4 & 9 & 13,6 & 66 & \multirow[t]{2}{*}{$0,000^{*}$} \\
\hline Memiliki & 26 & 8,2 & 292 & 91,8 & 318 & \\
\hline \multicolumn{7}{|l|}{ Sumber air } \\
\hline Tidak terlindung & 43 & 86,0 & 7 & 14,0 & 50 & \multirow[t]{2}{*}{$0,000^{*}$} \\
\hline Terlindungi & 40 & 12,0 & 294 & 88,0 & 334 & \\
\hline
\end{tabular}

Sumber: Data Primer, 2018 
Tabel 11. Faktor Risiko Stunting pada baduta di Sulawesi Tengah Tahun 2018

\begin{tabular}{|c|c|c|c|c|}
\hline Variabel & B & OR & $95 \% \mathrm{CI}$ & $\rho$-value \\
\hline Berat Lahir Rendah (X1) & 1,707 & 5,512 & $1,992-15,256$ & 0,001 \\
\hline Tidak Mencuci tangan (X2) & 1,679 & 5,359 & $1,758-16,341$ & 0,003 \\
\hline Tidak Memiliki Jamban (X3) & 2,077 & 7,398 & $2,072-30,714$ & 0,003 \\
\hline Constant & $-12,009$ & 0,000 & & 0,000 \\
\hline
\end{tabular}

Sumber: Data Primer, 2018

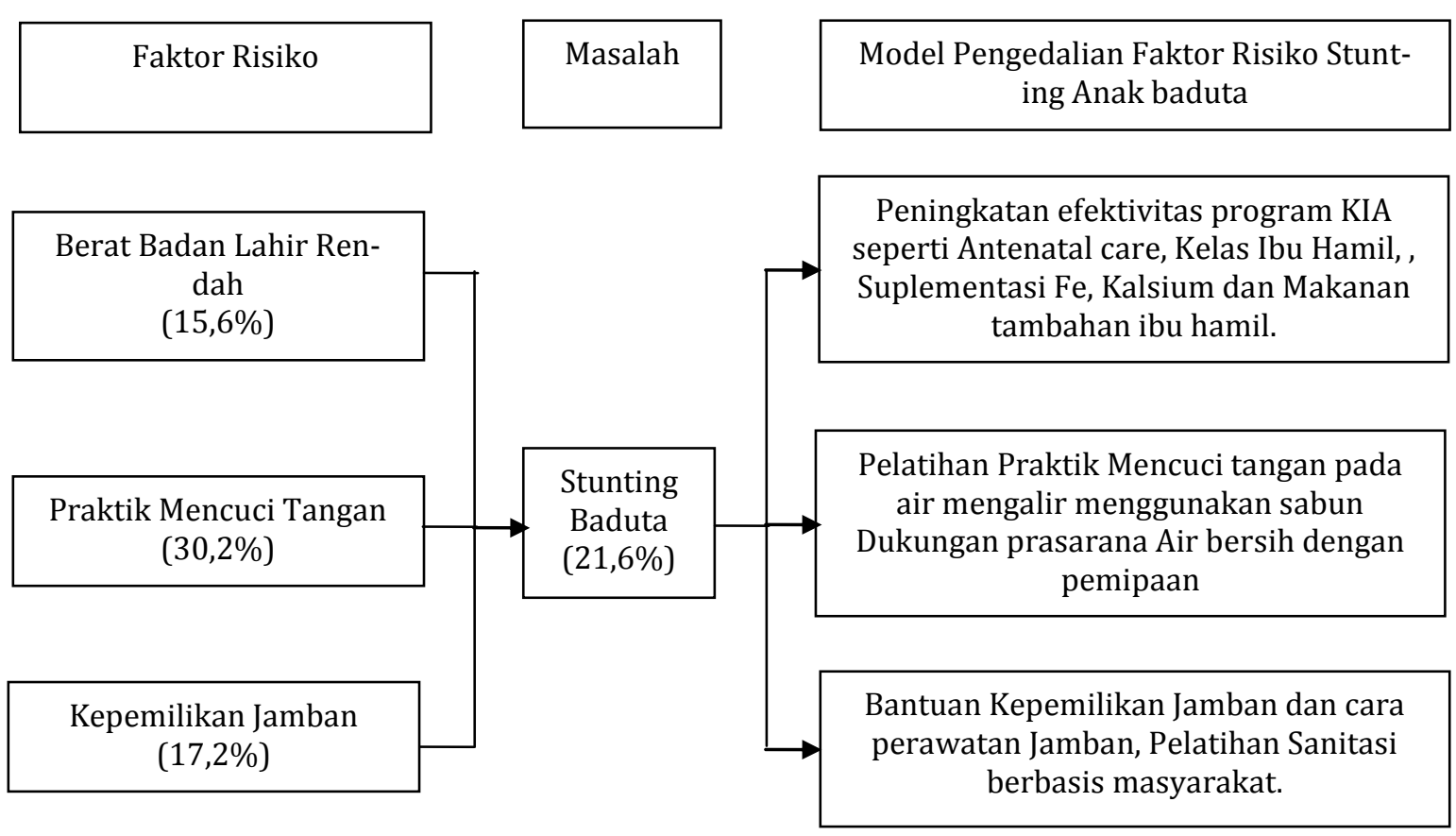

Gambar 1. Model Pengendalian Faktor Risiko Stunting Anak Baduta di Sulawesi Tengah 


\section{Tabel 11. Model MATCH Pengendalian Faktor Risiko Stunting Anak Baduta di Sulawesi Tengah Tahun 2018}

\begin{tabular}{|c|c|}
\hline Tahap & Langkah \\
\hline $\begin{array}{l}\text { 1. Menetukan } \\
\text { tujuan }\end{array}$ & $\begin{array}{l}\text { 1. Indikator kesehatan yang terpilih sebagai masalah kunci: } \\
\text { a. Berat Lahir Rendah }(15,6 \%) \\
\text { b. Perilaku tidak mencuci tangan }(30,2 \%) \\
\text { c. Tidak memiliki jamban }(17,2 \%) \\
\text { 2. Populasi yang teridentifikasi untuk perubahan perilaku adalah Ibu hamil, Ibu } \\
\text { menyusui/pengasuh anak dan Kepala keluarga. } \\
\text { 3. Perilaku yang relevan untuk dilakukan modifikasi adalah peningkatan } \\
\text { asupan gizi, pemberian Tablet Fe, Tablet kalsium, Antenatal care, praktik } \\
\text { cuci tangan menggunakan sabun pada air mengalir dan bantuan kepemilikan } \\
\text { jamban. } \\
\text { 4. Faktor lingkungan yang harus dicapai dalam mendukung kegiatan tersebut } \\
\text { diatas adalah ketersediaan pangan dan suplemen selama kehamilan, } \\
\text { ketersediaan air bersih dan ketersediaan jamban. }\end{array}$ \\
\hline $\begin{array}{l}\text { 2. Perencanaan } \\
\text { Intervensi }\end{array}$ & $\begin{array}{l}\text { 1. Intervensi utama kepada ibu hamil, ibu menyusui/pengasuh anak dan } \\
\text { kepala keluarga. Termasuk pula didalam rencana intervensi ini adalah ad- } \\
\text { vokasi hasil penelitian kepada kepala dinas kesehatan kabupaten Poso, } \\
\text { Banggai, Sigi dan Kota Palu. } \\
\text { 2. Rencana intervensi adalah: } \\
\text { a. Penguatan program ibu hamil, makanan bergizi, Tablet Fe dan Kalsium } \\
\text { b. Sosialisasi menggunakan media spanduk dan leaflet untuk cara mencuci } \\
\text { tangan menggunakan sabun dan air mengalir. } \\
\text { c. Memberikan bantuan jamban bagi masyarakt yang belum memiliki jam- } \\
\text { ban disertai cara pemeliharaan jamban. } \\
\text { 3. Kerangka intervensi berdasar pada hasil analisis penelitian dengan } 3 \text { pokok } \\
\text { masalah yaitu berat badan lahir, cuci tangan dan kepemilikan jamban. } \\
\text { 4. Pendekatan intervensi melalui media advokasi, komunikasi kesehatan dan } \\
\text { sesi pelatihan. }\end{array}$ \\
\hline $\begin{array}{l}\text { 3. Pengembanga } \\
\text { Program }\end{array}$ & $\begin{array}{l}\text { 1. Membentuk pusat studi stunting yang merupakan tempat bertemunya } \\
\text { peneliti, perwakilan pemerintah, akademisi dan lembaga donor. } \\
\text { 2. Membuat pedoman intervensi dan pedoman pelatihan } \\
\text { 3. Pengembangan pembelajaran penanggulangan stunting. } \\
\text { 4. Mengumpulkan bahan, persediaan, dan sumber daya lainnya dalam pusat } \\
\text { studi yang dibentuk. }\end{array}$ \\
\hline $\begin{array}{l}\text { 4. Persiapan Imple- } \\
\text { mentasi }\end{array}$ & $\begin{array}{l}\text { 1. Dukungan advokasi masyarakat melibatkan tokoh masyarakat dan tokoh } \\
\text { agama, dukungan dari dinas kesehatan, dinas sosial, dinas pemberdayaan } \\
\text { perempuan, dinas kebersihan dan dinas pekerjaan umum. Dan yang paling } \\
\text { utama adalah kesediaan dari populasi ibu hamil, ibu menyusui/pengasuh } \\
\text { anak dan kepala keluarga untuk berubah kearah perilaku yang diharapkan } \\
\text { program. } \\
\text { 2. Pelatihan pelaksana program }\end{array}$ \\
\hline 5. Evaluasi & $\begin{array}{l}\text { 1. Proses kelayakan intervensi, penerimaan, dampak terhadap hasil belajar } \\
\text { dilakukan } \\
\text { 2. Evaluasi dampak termasuk perubahan lingkungan, perilaku, variabel teori- } \\
\text { tis, dan variabel kognitif seperti pengetahuan dan sikap dilakukan } \\
\text { 3. Dalam evaluasi hasil, perubahan status kesehatan dengan mengukur kembali } \\
\text { indikator utama prevalensi stunting pada baduta. }\end{array}$ \\
\hline
\end{tabular}

